\title{
Class V Preparation in 44 and 45, Bond Preparation and Gingival Contouring with Erbium Laser (Er, Cr: YSGG) - Case Report
}

\author{
Alshaimaa Mohammed Alnaggar* and Mohamed Mahmoud \\ Dental Laser, AALZ. RWTH Aachen University, Germany \\ *Corresponding Author: Alshaimaa Mohammed Alnaggar, Dental Laser, AALZ. RWTH Aachen University, Germany.
}

Received: November 19, 2019; Published: November 26, 2019

DOI: 10.31080/ASDS.2019.03.0713

\begin{abstract}
According to high water and hydroxyapatite absorption by Erbium lasers, it become a powerful tool for selective caries removal and soft tissue applications, in this case report we used erbium chromium laser device Er, Cr: YSGG (2780nm), for enamel and dental preparation(class v) for right lower premolars, then did laser bond prep by create rough surface and gingival contouring, Patient agreed to start cavity preparation without a local anaesthetic.

Followed up the case after 3 months.

The results were painless procedure, fast, satisfied the patient during the procedure, furthermore contoured healthy gingivae and stable restoration in follow up visit.

No post-operative pain or complication was reported by patient.

Conclusion: Er, Cr: YSGG $(2780 \mathrm{~nm})$ selectively remove the caries with painless and more agreeable and satisfied method to the patient comparing to drilling way, also laser could make three different procedures with same device and wavelength with different parameters.
\end{abstract}

Keywords: Preparation; Contouring

\section{Introduction}

Class $\mathrm{v}$ had some challenges during preparation and after restoration, as risk of pulp exposure or gingival trauma with bur, microleakage after restoration, pulp intolerability due to heat production by highspeed handpiece.

Laser appliances remove dental caries selectively due to the water content in carious tissue. The erbium laser makes thermal changes in water molecules of the caries tissue, so the absorbed energy evaporates the water molecule inside carious tissue then vapor pressure causes micro explosive lead to ablation of carious tissue [1,2] figure 1 .

Additionally, opening dentinal tubules without formation of smear layer with laser irradiation, furthermore it can sterilize the surface significantly [3].

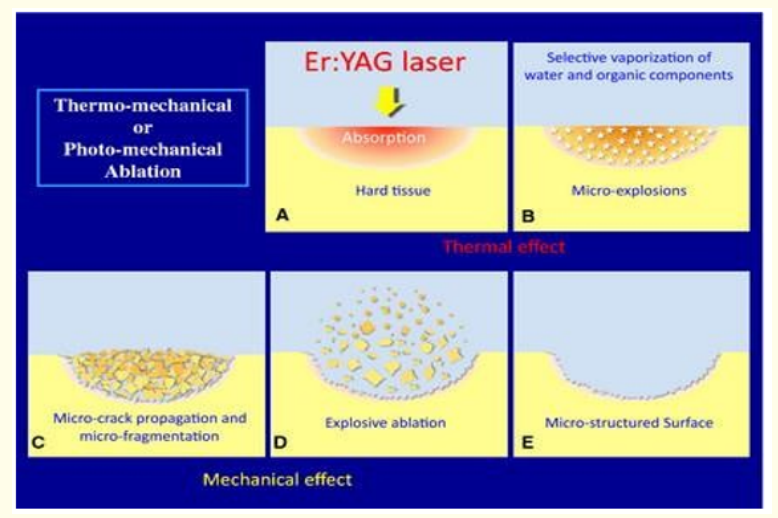

Figure 1: https://www.researchgate.net/figure/274900218_ fig18_Figure-3-Mechanism-of-hard-tissue-ablation-with- an-erbium-doped-yttrium-aluminium-garnet. 
Er, Cr: YSGG absorption coefficient to water $\left(4360 \mathrm{~cm}^{-1}\right)$ and hydroxyapatite $\left(400 \mathrm{~cm}^{-1}\right)$, depth penetration $2.28 \mu \mathrm{m}$ in water and $25 \mu \mathrm{m}$ in hydroxyapatite [4]. Which make this type of laser adequate to work with caries removal due to high content of water inside carious dentine as Carious dentine contain water $27-35 \%$ by volume and grossly carious dentine is $54 \%$ by volume while healthy dentine is $20 \%$ by volume.

So, it can be selective Thermo- mechanical ablation or Explosive water mediated ablation due to high absorption of erbium family (mid infrared radiation) $[5,6]$.

This can be done without any harm to pulp as Temperature at pulp chamber increase $2-3^{\circ} \mathrm{C}$, on surface $300-700^{\circ} \mathrm{C}$, while with drill 700 to $900^{\circ} \mathrm{C}$ on the surface $[7,8]$.

\section{Method}

35yrs old male, free medically, clinical finding: healthy gingivae, no abnormalities, normal periodontal pockets, caries class $\mathrm{v}$ in 44,45 and extend slightly sub gingivally figure 2 .
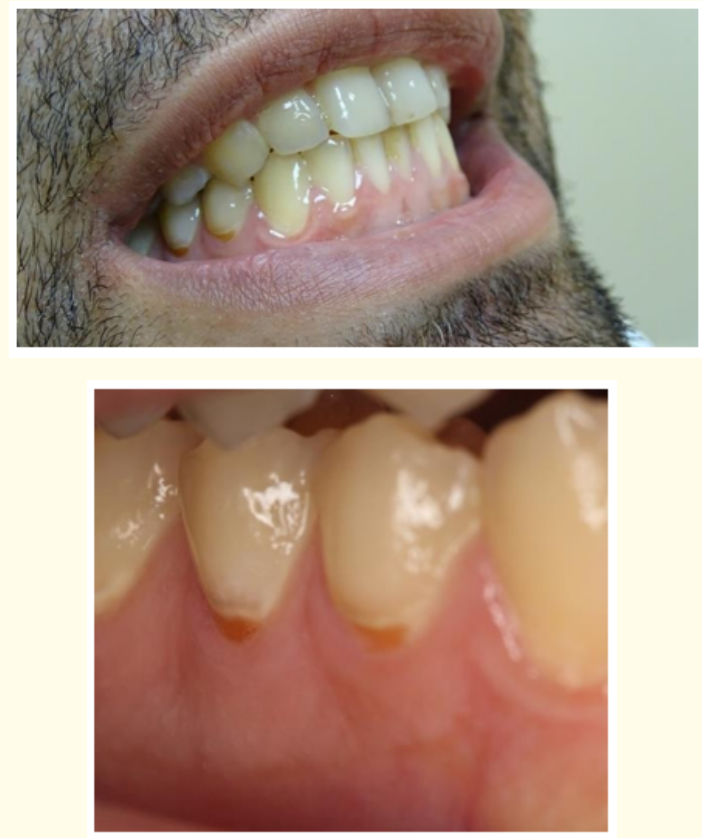

Figure 2: Caries class v 4445.

Pain with sweets in 45,44 last shortly was the chief complain of the patient.

The treatment plan

- To excavate caries safely without any harm of surrounding structures, using Painless procedure and disinfect the tooth.

- Then provide roughness for perfect marginal adaptation of restoration.

- Then applicate the restoration after contouring of gingivae.
Aim of using Er, Cr: YSGG was selective removal of caries, Safer procedure than high speed drill, Preservation of dental hard tissue, Bacterial elimination.

Treatment

- Informed consent was obtained; no anaesthesia was used.

- Adjust parameters in device (Waterlase I plus) 5.5W,15Hz, $80 \%$ water, 60\%air) then apply tip (MZ8 gold) with 45 degrees and non-contact for caries removal for class $v$ (Figure $3 a, b)$.

- Followed by Gingival contouring $(2.5 \mathrm{~W}, 50 \mathrm{~Hz}, 10 \%$ water, 10\%air) by Er, Cr: YSGG was done to provide access for caries removal sub gingivally and for better application of restoration figure 4 .

- Then did laser homeostasis, to stop the little bleeding for better isolation by using the following parameter $0.5 \mathrm{~W}$, $30 \mathrm{~Hz}, 1 \%$ water, $20 \%$ air, s mode, MZ5 Gold tip), Tip was non- contact by $1-3 \mathrm{~mm}$.

- Bond prep parameters adjusted (4.5W,50 $\mathrm{Hz}, 80 \%$ water,60\%water) to create roughness surface figure 5.

- Apply bond and incremental application of composite (3M) every increment was light cured for $40 \mathrm{~s}$.

- Polishing by carbide bur and sand paper disc.

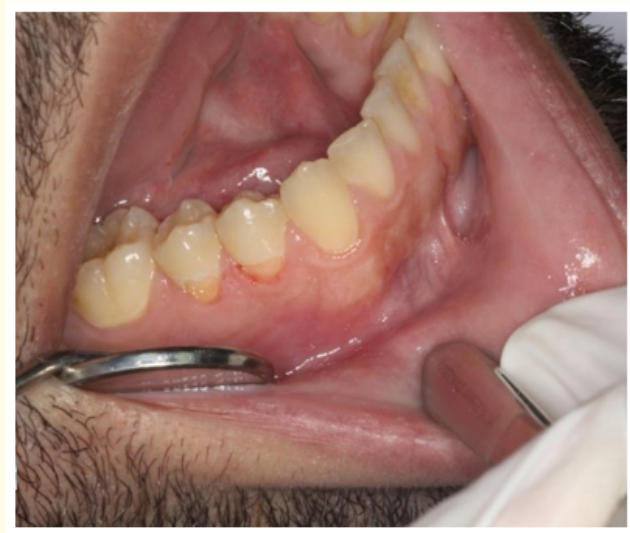

A

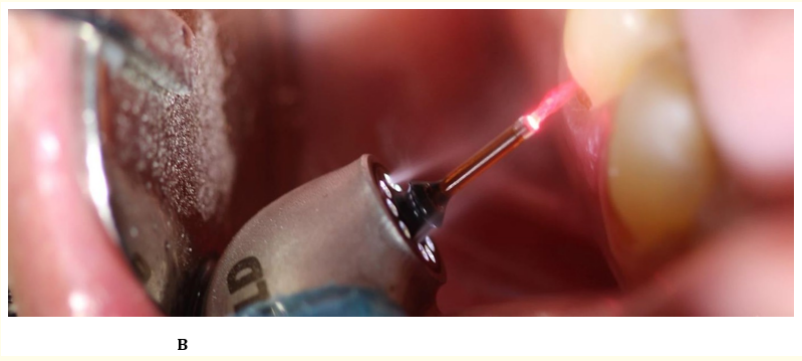

Figure 3: A AND B after cavity preperation $b$. tip direction to prep class $v$. 


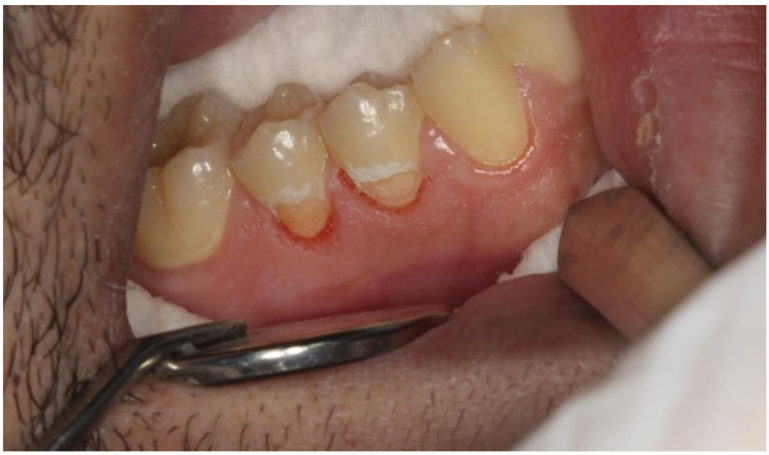

Figure 4: Gingival recontouring and bond preparation.

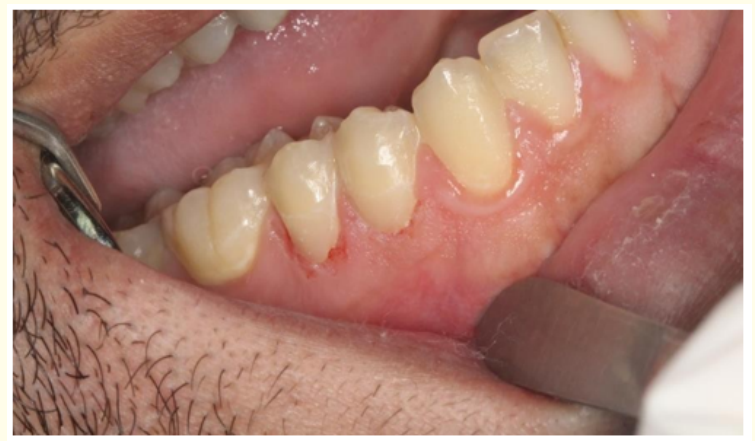

Figure 5: Immediate after composite restoration.

\section{Post-operative}

No post-operative pain or swelling was reported.

- $\quad$ Gingival healing was perfect in second visit figure 6.

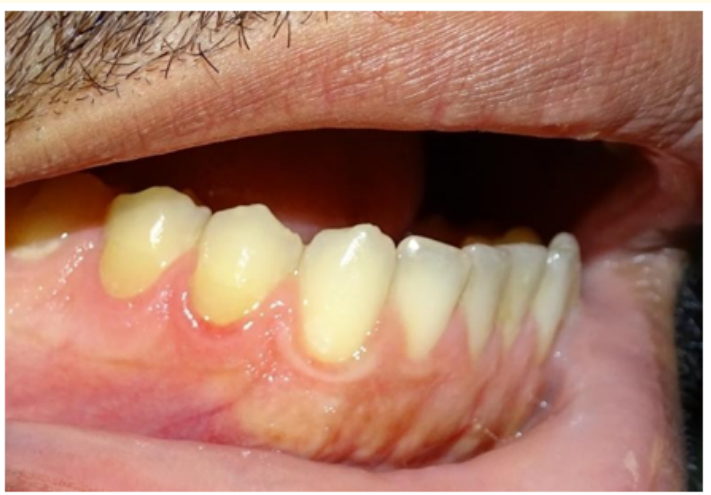

Figure 6: After 3months follow up.

\section{Discussion}

Mid-infrared radiation close to $3000 \mathrm{~nm}$, such as those emitted by the erbium lasers, have high absorption peak of water and hydroxyapatite figure 7 , and therefore it was demonstrated to be effective for cutting soft and hard tissues. The erbium lasers are Er: YAG (erbium: yttrium-aluminum-garnet, $2940 \mathrm{~nm}$ ) and Er, Cr: YSGG (erbium, chromium: yttrium- scandium-gallium-garnet, 2780 $\mathrm{nm}$ ), they were approved by the US Food and Drug Administration (FDA) for use in dental hard tissues in the late 1990s.

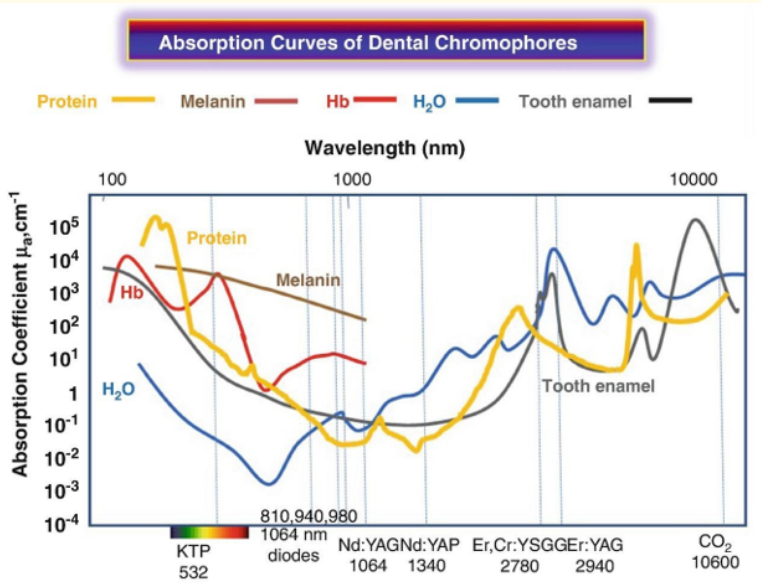

Figure 7: Picture accredited to Parker S. (2018) Laser/Light Application in Dental Procedures. In: Nouri K. (eds) Lasers in Dermatology and Medicine. Springer, Cham.

Bactericidal effect is another benefit for using erbium laser, with drill debris can cover dentinal tubules which will trap bacteria inside, in Er, Cr: YSGG shock wave effect deeper into tubules $(550 \mu \mathrm{m})$, it also dissociate water molecule to singlet oxygen $(\mathrm{OH})$ Which is highly toxic to bacteria, it was observed 0.3 to $0.5 \mathrm{~mm}$ bacteria elimination below surface, absence of smear layer and open dentinal tubules $[9,10]$.

The use of energy values below the ablation threshold (subablative) allowing a microstructural modification in dentin and enamel creates a very similar surface to that obtained with phosphoric acid in bond prep protocol [11,12].

In most cases, local anaesthesia injection is not required, due to an analgesic effect which erbium triggers in just a few seconds. This laser allows pain-free ablation of hard tissues. 
Furthermore, the operator must have an in-depth knowledge on how to set and modify the various parameters (among which energy output, frequency of pulses, and the air/water ratio [2,13].

\section{Conclusion}

Erbium lasers (2940 $\mathrm{nm}$ and $2780 \mathrm{~nm}$ ) are selectively remove of carious tissue and cavity preparation. However, the successful treatment relies not only on the tissue composition and laser parameters, but also on the professional's knowledge.

\section{Bibliography}

1. Hadley J., et al. "A laser-powered hydrokinetic system for caries removal and cavity preparation". The Journal of the American Dental Association 131.6 (2000): 777- 785.

2. Niemz MH. "Laser-tissues interactions - Fundamentals and applications”. Berlin: Springer-Verlag, (2004).

3. Ceballos L., et al. "Microleakage of composite restorations after acid or Er- YAG laser cavity treatments". Dental Materials 17.4 (2001): 340-346.

4. Diaci J and Gaspirc B. "Comparison of Er: YAG and Er, Cr: YSGG lasers used in dentistry". Journal of the Laser and Health Academy 2012.6 (2012): 1855-9913.

5. Rodríguez-Vilchis LE., et al. "Morphological and structural changes on human dental enamel after Er: YAG laser irradiation: AFM, SEM, and EDS evaluation". Photomedicine and Laser Surgery 29.7 (2011): 493-500.

6. $\quad$ De Moor RJ and Delmé KI. "Laser-assisted cavity preparation and adhesionto erbium-lased tooth structure: Part 1. Laserassisted cavity preparation". The Journal of Adhesive Dentistry 11 (2009): 427-438.

7. Attrill DC., et al. "Thermal effects of the Er:YAG laser on a simulated dental pulp: a quantitative evaluation of the effects of a water spray". Journal of Dentistry 32.1 (2004): 35-40.

8. Zach L and Cohen G. "Pulp response to externally applied heat”. Oral Surgery, Oral Medicine, Oral Pathology 19 (1965): 515-530.

9. Belikov AV., et al. "Bacterial activity in the products of laser destruction of human dental enamel and dentin". Stomatologiia (Mosk) 74.6 (1995): 32-34.
10. Gordon W., et al. "The antimicrobial efficacy of the erbium, chromium: yttrium-scandium- gallium-garnet laser with radial emitting tips on root canal dentin walls infected with Enterococcus faecalis". Journal of the American Dental Association 138.7 (2007): 992-1002.

11. Akin GE., et al. "Bond strengths of one-step self-etch adhesives to laser-irradiated and bur-cut dentin after water storage and thermocycling". Photomedicine and Laser Surgery 30.4 (2012): 214-221.

12. Gutknecht N., et al. "Microleakage of composite fillings in Er, Cr: YSGG laser-prepared class II cavities". Lasers in Surgery and Medicine 28 (2001): 371-374.

\section{Volume 3 Issue 12 December 2019}

(c) All rights are reserved by Alshaimaa Mohammed Alnaggar and Mohamed Mahmoud. 